
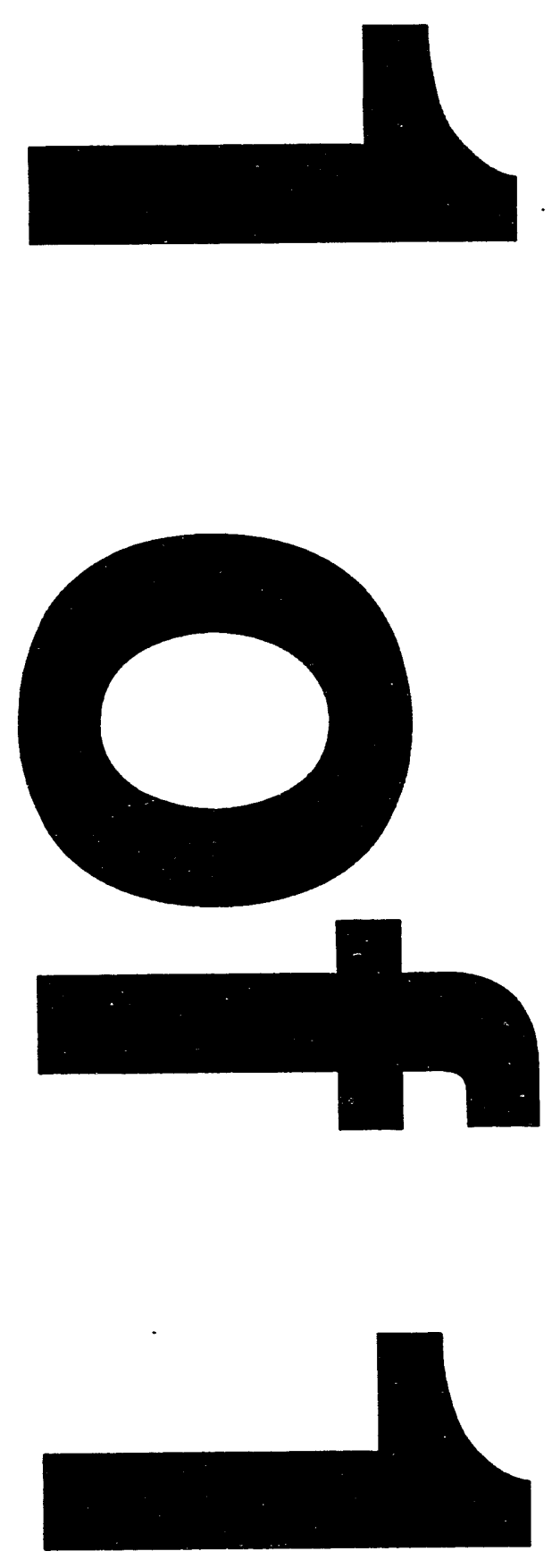


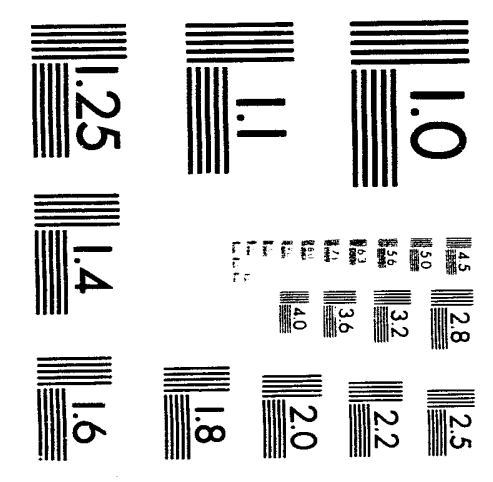




\title{
Primary Standards Laboratory Report 1st Half 1993
}

\author{
Measurement Standards Department \\ Sandia National Laboratories \\ Albuquerque, NM 87185
}

\begin{abstract}
Sandia National Laboratories operates the Primary Standards Laboratory for the Department of Energy, Albuquerque Operations Office (DOE/AL). This report summarizes metrology activities that received emphasis in the first half of 1993 and provides information pertinent to the operation of the DOE/AL system-wide Standards and Calibration Program.
\end{abstract}




\section{Foreword}

This report was compiled and edited by W. G. T. Levy, Sandia National Laboratories. Additional information on the activities covered in this report may be obtained by contacting W. G. T. Levy, Measurements Standards Department 1043, Sandia National Laboratories, PO Box 5800, Albuquerque, New Mexico 87185, telephone (505) 845-8268. 


\section{Contents}

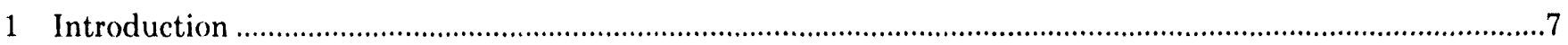

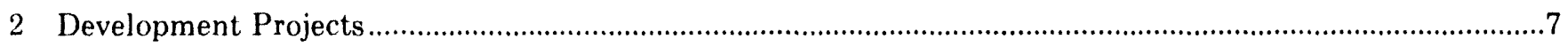

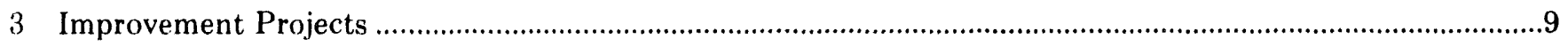

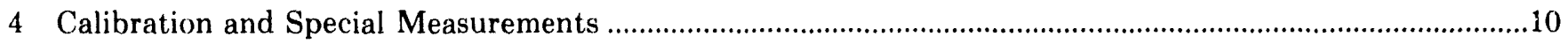

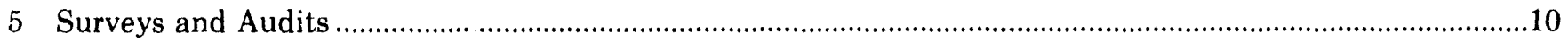

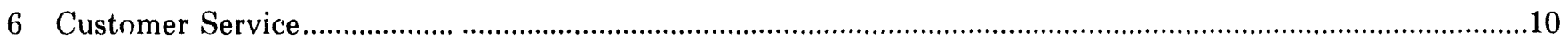

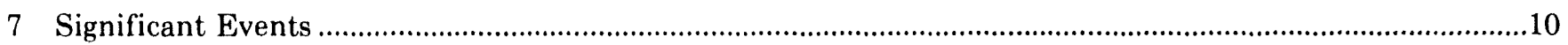

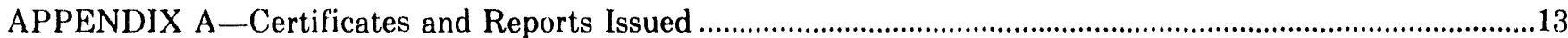

APPENDIX B -Commercial Calibration Laboratories (CCLs) .............................................................................15

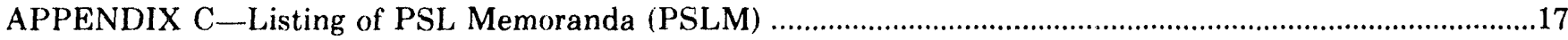

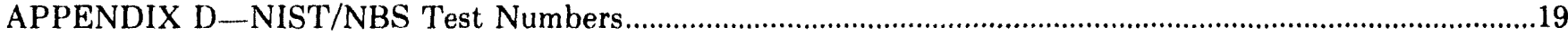

APPENDIX E-DOE/PSL Memoranda on Standards and Calibration Program ….............................................21 


\section{Primary Standards Laboratory Report 1st Half 1993}

\section{Introduction}

The Primary Standards Laboratory (PSL) operates a system-wide primary standards and calibration program for the U.S. Department of Energy, Albuquerque Field Office (DOE/AL). The PSL mission is as follows: to develop and maintain primary standards; to calibrate electrical, physical, and radiation reference standards for customer laboratories (DOE/AL nuclear weapon contractors); to conduct the technical surveys and measurement audits of these laboratories; and to recommend and implement system-wide improvements.

This report summarizes activities of the PSL for the first half of 1993 and provides information pertinent to the operation of the DOE/AL Standards and Calibration Program. Specific areas covered include development projects, improvement projects, calibration and special measurements, surveys and audits, customer service, and significant events. Appendixes include certifications and reports; a discussion about commercial calibration laboratories; PSL memoranda (PSLM); test numbers from the National Institute of Standards and Technology (NIST), formerly the National Bureau of Standards (NBS); and DOE/PSL memoranda on the Standards and Calibration Program with emphasis on traceability of PSL calibrations.

\section{Development Projects}

\section{Digitally Synthesized Source}

NIST is developing for the PSL an improved version of the Digitally Synthesized Source (DSS). The improved DSS will provide IEEE 488 bus control of the frequency, waveform, and RMS output voltage level and improved resolution, dc offset adjustment, and less harmonics in the output signal. The new DSS will produce any of 16 selectable voltage waveforms over the low-frequency range, from 1 to $5,000 \mathrm{~Hz}$. The first unit has been delivered to the PSL and has been placed in operation. Problems with software compat- ibility between the various computer systems at NIST and at the PSL have been resolved. NIST will produce 15 of the low-frequency DSS units for use at the PSL and at the Contractor Standards Laboratories (CSLs). In addition a few prototype high-frequency units that function to $100 \mathrm{kHz}$ will be delivered for use in the PSL. NIST expects to complete all units by the end of 1993, as scheduled. A step-by-step calibration procedure for calibrating the DSS up to $5,000 \mathrm{~Hz}$ will be provided to each CSL.

\section{Development of Techniques for Calibrating Waveform Recorders}

The development of techniques for calibrating waveform recorders (transient waveform digitizers) is proceeding. Work performed earlier in the year on sine wave calibrations was discussed in the paper "The Use of DFT Windows in Signal-to-Noise Ratio and Harmonic Distortion Computations," which was presented at the 1993 IEEE Instrumentation and Measurement Technology Conference. Recent work has concentrated on methods based on sine wave fitting. The output of many sine wave generators (HP 3325, HP 8657, HP 8116, and Efratom Rubidium Frequency Standard) contains too much phase noise and harmonic distortion for this type of calibration work. Long-term measurements of the magnitude of sine waves from these generators exhibited diurnal variations that seemed to be correlated with room temperature variations. Other sine wave generators (including Fluke 6082, HP 8662, and Novatech 2910) have phase noise specifications that are suitable for calibration work; however, these generators have too much harmonic distortion. The harmonic distortion can be removed with 11-pole elliptical filters such as those manufactured by TTE, Inc.

NIST completed work on identifying and quantifying the main sources of uncertainty in sine wave fitting. NIST is characterizing the current version of their sampling comparator probe for static linearity, harmonic distortion, gain flatness, and temperature coefficient. NIST is also investigating the effect of time-base uncertainties on measurements with 
the probe. Software was written to estimate timing jitter from sine wave measurements. A paper on this method, "Estimation of Timing Jitter in Digitized Sine Waves," will be presented by Otis Solomon (of the Primary Electrical Standards Department) at the 1993 National Conference of Standards Laboratories meeting in Albuquerque, New Mexico.

\section{Inductive Voltage Divider Calibration System}

NIST is developing for the PSL an automated system for the calibration of inductive voltage dividers (IVD) (or ratio transformers). This system is modeled after the system that NIST recently completed for the NASA ZENO experiment. The ZENO project required calibration of ratios to 10 parts per billion and this requirement was met. NIST expects to meet the scheduled delivery of a complete IVD calibration system to the PSL by the end of December 1993.

\section{Time and Frequency}

The global positioning system (GPS) clock used by the PSL to establish time of day failed in service but has been repaired and placed back in service. Two of the three HP 5061A cesium-beam frequency standards that provide the PSL standard frequencies failed in service and were replaced with two HP 5071A primary frequency standards. The HP 5071A units have been placed in service and are providing standard frequencies to an uncertainty of approximately 1 part in 10 to the twelfth.

The design for the antenna system for the Weapons Program Primary Standards Laboratory (WPPSL) has been completed. Facilities reviewed the specifications, modified them to meet their requirements, and sent a final purchase requisition to Sandia Purchasing. The design for the frequency distribution system inside the WPPSL building, which will deliver a $100 \mathrm{KHz}, 1 \mathrm{MHz}$, or $5 \mathrm{MHz}$ signal to laboratory areas, has similarly been completed and sent to Sandia Purchasing.

\section{Low-Range Flow Generator}

A contract was issued to NIST for the development and fabrication of hardware that will be used to generate very low gas flows. The new system will generate flows between $1 \mathrm{E}-11$ and $1 \mathrm{E}-6 \mathrm{mols} / \mathrm{s}$ (2E-7 to $2 \mathrm{E}-2 \mathrm{~atm} \mathrm{~cm}^{3} / \mathrm{s}$ at $0^{\circ} \mathrm{C}$ ) with uncertainties between 3 and $1.5 \%$. These flows will be used with orifice-flow pressure standards to calibrate vacuum gauges such as spinning rotor gauges, capacitance diaphragm gauges, and ionization gauges. The new system is scheduled to be completed by the end of 1994 .

\section{Chemical Standards Development Project}

Chemical Standards Development Project personnel have continued to examine a Sandia stockpile quality document (SS306587, Issue J) that specifies how weapon bodies are to be analyzed for internal gases. We believe the procedures in this document are lacking, because traceability of reference materials and approval of reference-material suppliers is not adequately specified. The document has been discussed with its owner (in Stockpile Evaluation Department I), the Merren committee, and PSL management. A proposed "mini-round-robin" to qualify a reference-material supplier was discussed in a recent chemical-standards working-group meeting (see below). Discussions are ongoing among a PSL representative (J. W. Guthrie), the SSL chemical-standards representative (W. F. Windle), and the Pantex CSL chemical-standards representative (M. R. Mitchell).

The chemical-standards project leader worked with the PSL computer project and other PSL personnel involved with Commercial Calibration Laboratory/Designated Calibration Source (CCL/ DCS) approval and oversights to define a database format for CCL/DCS entries. This format has been implemented on the PSL VAX 4000 and has gone through some evolution. During the recent chemicalstandards working-group meeting (see below), there was enthusiastic response from all CSL chemicalstandards representatives present for access to such a database.

Chemical-standards project personnel were given a special assignment to visit "donor" contractors in the DOE/Nuclear Weapons Contractor (NWC) and identify unique calibration and standards activities or capabilities that might be lost in the transfer of production responsibility from the donor sites (Martin Marietta Specialty Components, Mound, and Rocky Flats) to "receiver" sites (SNL/NM, LANL, and Allied-Signal/Kansas City Division). The assignment involved travel to all donor sites, visits with their CSL managers and other production managers, and preparation of a report to DOE/AL. The final report was presented to DOE/AL on May 13, 1993. Part of the report was a lecommendation that the various receiver site reconfiguration teams should have a standards person as a member.

Chemical standards project personnel arranged and hosted a chemical-standards working-group meeting in Albuquerque on June 16 and 17, 1993. 
This working-group meeting met its goals in that chemical-standards representatives from around the $\mathrm{DOE} / \mathrm{NWC}$ became acquainted and shared reports on their status, needs, and goals. The PSL chemicalstandards project received valuable input for the chemical-standards PSLM that is currently being drafted.

\section{Improvement Projects}

\section{Automated System for Inductor Measurements}

An automated system for inductance measurement has been designed and fully characterized in the AC Project. The system uses a General Radio Model GR1693 bridge under computer control to compare the unit under test with a PSL standard calibrated by NIST. This system will undergo a complete system review during August 1993 and will then be placed in operation for the calibration of standard inductors such as the General Radio Type 1480 Series.

\section{High-Voltage Laboratory Environmental Controls}

Temperature and humidity control problems in the High-Voltage Laboratory have been corrected by replacing the pneumatic temperature controller with an electrical controller. The new controller has a wider selection of control options and is better able to maintain temperature control with our aging environmental control system.

\section{Waveguide for Josephson Voltage Standard}

The conventional waveguide in the Josephson Voltage Standard has been replaced by a dielectric waveguide. This reduces the heat leakage into the dewar and therefore reduces the rate of liquid helium evaporation.

\section{Resistor History Database}

The project's extensive resistor history database is being entered into the Ingres database program on the PSL VAX. The data can be recalled into the Excel Spreadsheet program for examination and analysis. This work is being done by a Youth Opportunity Trainee summer student employee.

\section{Upgraded Certification of HP8753 VANA Performance}

An improved program, CERT8753Bu, for certifying the reflection coefficient measurement uncertainties of the Hewlett Packard 8753 Vector Automatic Network Analyzer (VANA) has been developed and placed into service. Improvements offered by the improved program include:

- HP8753 VANA uncertainties (at frequencies where air lines may be used) on large reflection coefficient measurements are now about \pm 0.02 compared with previous values as large as \pm 0.2 .

- The operator may now specify the confidence level (between 81 and 99 percent) at which reflection coefficient uncertainties (at any frequency) are reported. (Computer computation time requirements are significantly greater for the higher confidence levels.)

The first improvement resulted from the use of the Thru-Reflect-Line (TRL) technique for evaluation of uncertainty model parameters. The TRL technique requires the use of only three certified values and their small associated uncertainties. The prior technique required the same three certified values in addition to three other certified values, two of which have large uncertainties. Furthermore, the prior technique required "ideal characteristics" assumptions regarding two other "calculable standards"; the TRL requires no such assumptions. Elimination of the two large uncertainties accounts for most of the uncertainty reduction.

The second improvement resulted from (a) use of a more focused method for incorporating the effects of uncertainties on the standards used in the certification process and (b) use of nonparametric statistics to characterize the effects of those uncertainties.

\section{P-Delta-V Leak Calibration System}

Sandia's Manufacturing Technologies Center has completed welding and assembly of the vacuum manifold for the new P-Delta-V Calibration System. The pneumatic valve controller, assembled by Electronic Fabrication Department, Team A, has been tested and shown to be operational. A Statement of Work for the manifold's temperature-control enclosure has been drafted and will soon be submitted to suppliers for quotation. The electronics console and vacuum pumping system are next in line for design consideration. Mechanical completion, not including software and testing, is estimated to occur about mid-1094. 


\section{Ruska X-Float and Low-Pressure Air Dead-Weight Systems}

All the necessary upgrade components have been received from Ruska and Volumetrics to extend the calibration range of these systems from 600 to 1,000 psi. Included are a gas-control module from Volumetrics; a high-pressure, 1,000-psi piston; a mediumpressure, 100-psi piston; and additional weights from Ruska. While NIST calibrates the new pistons and the PSL calibrates the new weight set, the calibration systems will be modified to handle the higher pressures. This higher pressure capability is expected to be on line in early 1994.

\section{Calibration and Special Measurements}

\section{Josephson Array Round Robin}

The DC Project is participating in the Josephson Array Round Robin, sponsored by the National Conference of Standards Laboratories. 'Twelve laboratories, including NIST in (raithersburg, Maryland, are participating in the Round Robin, which will use four 10-V solid-state voltage standards.

\section{Surveys and Audits}

\section{Technical Surveys}

During this period, the PSL conducted four surveys of regular CSLs and a survey report was written for one of the technical surveys.

\section{Measurement Audits}

Twenty-eight measurement audits were initiated with the CSLs during this period. Seven measurement audit reports were written on audits previously completed. These included the five handcarry audits reported as part of the survey report discussed above, under Technical Surveys.

\section{Customer Service}

\section{PSL Customer Service Representative - Inquiries}

The PSL customer service representative has received 43 inquiries during this reporting period. All have been resolved as of this writing.

\section{Significant Events}

\section{New Weapons Production Primary Standards Laboratory}

The problem with the cementitious topping for the laboratory floors has been resolved. A contractor installed a new metal screen on the floor and joined it to the existing metal at the walls to maintain the integrity of the electromagnetic interference (EMI) shield. A new cementitious topping was poured over the screen. Initial tests on the topping material have shown that design strength was achieved. Additional tests, conducted over longer periods, on adherence to the main slab have shown some localized problems. Studies of these localized areas are ongoing.

Sandia's Communications Department reviewed the voice/data plans for the building and stated that the plans are not current with Sandia's overall communication plans. All buildings using designs that were initiated before Sandia's plans were generated are having this problem. A compromise position has been reached in which the voice/data plan for WPPSL, will be modified to meet the Sandia communication plan, but actual rework will be minimized. Facilities Fngineering Department now estimates completion of building shell work in October or early November 1993.

All details of layout for occupancy have been completed, and the bid package for Occupance Construction is being prepared.

\section{Publications}

1. L. K. Warne, R. I). Moyer, T. E. Koontz, and M. E. Morris, "A Radial 'Transmission Line Material Measurement Apparatus," SANI)92-2788, May 1993.

2. O. M. Solomon, Jr., "The Effects of Windowing and Quantization Error on the Amplitude of Frequency-Domain Functions," IEEE Transactions on Instrumentation and Measurement, 41 , pp. 932$937,1992$.

3. O. M. Solomon, Jr., "The Use of DF'T Windows in Signal-to-Noise Ratio and Harmonic Distortion 
Computations," 1993 IEEE Instrumentation and Measurement Technology Conference, May 18-20, Irvine, CA.

\section{CCL/DCS Database}

A database was established to track calibration services from CCLs and DCSs. Three associated programs were written: one to input new records, one to modify records, and one to view records. The database is not populated yet, but a few records are there. The database programs can be accessed from the main recall system menu or view only with the free (captive) account LABCAT on the PSL VAX.

\section{Customer Inquiry Database}

Another database was established to track customer inquiries. As with the CCL/DCS database, the customer inquiry also has three associated programs: one to input new records, one to modify records, and one to view records. The customer inquiry database can be accessed only from the main recall system menu on the PSL VAX.

\section{Uncertainties}

An internal PSL committee is developing a guidance document to address (a) the PSL's process for obtaining uncertainties and (b) the customer's use of PSL uncertainties. PSL personnel have just reviewed this document, and it should be ready for comments from the CSLs in late 1993. PSL uncertainty at the time of test will generally be based on a root-sumsquare (RSS) combination of uncertainty components expressed as standard deviations. This follows the International Organization for Standardization/ International Bureau of Weights and Measures (ISO/ BIPM) "Guide to the Expression of Uncertainty in Measurement" as well as NIST Guideline TN 1297, which will direct NIST uncertainty statements after January 1, 1994. Additional uncertainty components required by AL57XA (such as those for use conditions, drift, and shipping) will be incorporated by RSS or by adding the ranges of these other uncertainty components to any safety factors. In contrast to NIS'T's choice of a 95-percent level of confidence, the PSL will use a 99-percent (or better) level.
In general, customers should add their own uncertainty to that given by the PSL. If the customer has requested from the PSL a breakdown of the uncertainty into an RSS component and a range component, the customer may RSS their appropriate components and add in the ranges.

\section{Special Temperature Training}

Special training in temperature measurements was provided to a metrologist from EG\&G Energy Measurements, Las Vegas, Nevada, during the week of March 22 through 26, 1993, at the Sandia PSL. The training involved the annealing of their standard platinum resistance thermometer (sprt), the triple point of water and mercury, ac bridge use, data analysis, etc. As a result, further training was requested. During the week of June 28 through July 2, six metrologists at EG\&G were trained in their laboratory using their instruments and available equipment. The items discussed included preparation of a triple point of water using a cold rod and liquid nitrogen, intercomparison of a $25-\mathrm{ohm}$ resistor that had been measured at the PSL by several methods, some of the subtleties of the ITS-90 temperature scale and sprt's, and uncertainties.

\section{PSL Business Plan}

The Primary Standards Program Office issued a business plan on March 5, 1993. The plan was patterned after the Malcolm Baldrige 1992 Award Criteria and addressed such diverse areas as strategic quality planning, human resource development, and customer focus and satisfaction, as well as several other important quality concerns. A revision is planned by the end of October 1993.

\section{Strategic Business Review}

A strategic business review of the PSL was completed and a report distributed on June 11, 1993. The scenarios and impacts ranged from the PSL as a center of excellence to the PSL as an oversight function only. A business review of the system-wide standards laboratory operations throughout the NWC might be a logical next step. 


\section{APPENDIX A \\ Certificates and Reports Issued}

The certificates and reports issued by the PSL are summarized in this appendix.

Reference Standards for

Allied Signal, Inc., Kansas (ity Division 62

EG\&G Energy Measurements Inc., Las Vegas, NV 21

Martin Marietta Specialty Components, Inc. 34

Lawrence Livermore National Laboratory 3

Los Alamos National Laboratory 51

Mason and Hanger-Silas Mason Co. 37

EG\&G Mound Applied Technologies, Inc. $\quad 48$

Martin Marietta Energy System Inc.,

Oak Ridge Y-12 Plant 1

EG\&G Rocky Flats Plant 24

Sandia National Laboratories/New Mexico 45

Sandia National Laboratories/California 28

Westinghouse Savannah River Laboratory $\quad$ Subtotal $\quad \frac{13}{367}$

Other Reference Standards and Delegated Instruments 414

Special Measurements $\quad$ Subtotal $\frac{11}{425}$

Total $\underline{792}$

Total Active Items Currently in Recall System $\quad 5,297$ 


\section{APPENDIX B}

\section{Commercial Calibration Laboratories (CCLs)}

The latest revision to AL57XA (Rev. 1, October 22, 1990) substantially changes the amount of guidance for the approval and oversight of commercial suppliers of calibrations for the Nuclear Weapons Complex, i.e., "Commercial Calibration Laboratories." A CCL is defined in the new Order as:

"A subcontractor who has been approved by either the DOE, a contractor, or the Primary Standards Laboratory (PSL) to perform calibrations on measurement standards and M\&TE."

Revision 1 of the Order provides for a variation in "the extent of approval and oversight" based on "the complexity of the product or services provided"; it does not explicitly characterize a CCL as was done in the earlier revision as Designated Commercial Standards Laboratory (DCSL) or Commercial Calibration Source (CCS).

This revision also requires each contractor to "maintain and provide to the PSL documented procedures for the approval and oversight of CCLs" (for review and oversight as part of the regular 'Technical Survey function).

Since the amount of specific guidance is reduced in Revision 1 of AL57XA itself, DOE/AL plans to provide more specific guidance in the form of a Primary Standards Laboratory Memorandum (PSLM) being prepared by the PSL and to be released after DOE/AL approval.

However, because certain necessary elements in the latest draft of the PSLM and comments from other sources appeared to modify the requirements of Revision 1 of $\mathrm{AL}$ Order 57XA, DOE/AL also plans to issue a new revision (Revision 2) as a Supplemental Directive that will include these necessary elements. At that time, DOE/AL will also approve the issuance of a compatible PSLM. Supplemental Directive 57XA (Revision 2) was just released, and the PSLM is anticipated during the first half of CY 1994.

Since the contractor programs are still currently evolving at various rates and have not yet achieved sufficient commonality between programs (including Revision 2 and PSLM requirements) to permit unrestricted use of CCLs between contractors, and because of legal issues that must be resolved, the usual list of commercial sources of calibration services is not included in this issue of the PSL Semiannual Report.

Questions regarding this matter should be addressed to W. G. T. Levy of the PSL Surveys and Audits Project, (505) 845-8268. 


\section{APPENDIX C \\ Listing of PSL Memoranda (PSLM)}

Over the years the PSL has issued various memoranda that provide general technical requirements and standards of good practice for the CSLs. These memoranda are listed here by number. A review for possible update, addition and/or obsoletion of these PSLMs is continually under way at the PSL. A copy of the latest index of the PSLM will appear in each semiannual report. 'The current issue reflected herein is Rev. 5 dated $7 / 19 / 89$. (No changes have occurred through this reporting period.)

\begin{tabular}{|c|c|c|}
\hline $\begin{array}{c}\text { PSLM } \\
\text { No. }\end{array}$ & Date & Title \\
\hline $1 \mathrm{~A}$ & $7 / 09 / 80$ & Exceptions to Recall Requirements \\
\hline 2 & $1 / 14 / 70$ & (standard leak terminations) ${ }^{* *}$ \\
\hline $3 \mathrm{~B}$ & $5 / 16 / 88$ & Laboratory Environments \\
\hline $5 \mathrm{E}^{* *}$ & $7 / 19 / 89$ & Calibration Obtained from Other than the Primary Standards Laboratory \\
\hline $11 \mathrm{~A}$ & 3/06/72 & Gage Block Materials \\
\hline $13 \mathrm{~B}$ & $11 / 20 / 86$ & Packaging Requirements for Shipment of Standards \\
\hline 14 & $11 / 20 / 74$ & Designated Commercial Standards Laboratories \\
\hline $20 \mathrm{~B}$ & $1 / 30 / 89$ & Rating and/or Reporting for 'Technical Surveys and Measurement Audits \\
\hline 23 & $6 / 05 / 80$ & NBS Calibrated Standards \\
\hline $24 \mathrm{~A}$ & $7 / 18 / 86$ & Weights to be Calibrated by the PSL \\
\hline 26 & $3 / 30 / 83$ & Checking and Cross-Checking of Standards \\
\hline $27^{* *}$ & $7 / 19 / 89$ & Reference Materials \\
\hline
\end{tabular}

* Missing PSLM numbers were obsoleted in Rev. 5 or earlier revisions.

** PSLMs still in force affected in Rev. 5 (PSLMs 5E and 27, together, replace PSLM 5D, Calibration Service Not Available from the Primary Laboratory; PSLM 15, Cross Utilization of Contractor Standards Laborutories; and PSLM 22, Calibration Below Reference Standard Level). 


\section{APPENDIX D \\ NIST/NBS Test Numbers}

Following is a list of some of the presently valid NIS'T/NBS' test numbers assigned to reports of tests performed for the PSI, including some of the more frequently used st andards. However, where traceability is questioned hy first-tier suppliers and others outside the I)OF/AL Weapons Complex, it is the mosition of both the DOE/AI and PSL that the memorandum on traceability dated November 25, 1991. written with the concurrence of the DOE/AL, be used to answer such questions. A copy of this memorandum along with DOF's cover memorandum and transmittal letter are reprinted herein for ready reference.

\begin{tabular}{|c|c|}
\hline Standard & $\begin{array}{l}\text { NIST/NH } \\
\text { Test No }\end{array}$ \\
\hline ar Voltage & 809920 \\
\hline ac Ciurrent & $521 / 240751$ \\
\hline High-Frequency Inductance & $808: 351$ \\
\hline C'apacitance & 249663 \\
\hline High-Frequency (apacitance & $8114: 39$ \\
\hline Self Inductance & 249001 \\
\hline de Resistance (Thomas 1 ( 2$)$ & $811 / 250261$ \\
\hline $\begin{array}{l}\text { (hi value } \\
\text { resistors) }\end{array}$ & $811 / 250182$ \\
\hline High Voltage Resistor & $881 / 250161-92$ \\
\hline High-Voltage Pulse & $728 / 250161-92$ \\
\hline (iage Blocks, Iong English & $821 / 251200-93$ \\
\hline (iage Blocks, Long Metric & $821 / 251200-93$ \\
\hline Ciage Blocks, Angle & $821 / 249554-92$ \\
\hline Find Standards & $821 / 250779-92$ \\
\hline 'Threadwires (Fnglish) & $821 / 249762-92$ \\
\hline Threadwires (Metric) & $821 / 252109-93$ \\
\hline Master Steel Balls (English) & $821 / 251866-93$ \\
\hline Master Steel Balls (Metric) & $821 / 247725-91$ \\
\hline Optical Flats & $731 / 244765-89$ \\
\hline
\end{tabular}

\begin{tabular}{|c|c|}
\hline Standard & $\begin{array}{l}\text { NIST/NBS } \\
\text { Test No. }\end{array}$ \\
\hline Surface Roughness Standards & $731 / 244563-89$ \\
\hline \multicolumn{2}{|l|}{ Force (Proving Rings) } \\
\hline $5000 \mathrm{lbf}$ & $822.07 / 248918$ \\
\hline $10,000 \mathrm{lbf}$ & $822.07 / 248127$ \\
\hline $20,000 \mathrm{lbf}$ & $822.07 / 2525 \check{26}$ \\
\hline $60,000 \mathrm{lbf}$ & $732.07 / 245921$ \\
\hline $100,000 \mathrm{lhf}$ & $732.07 / 244961$ \\
\hline Pressure, Air (Ruska-F/N 4171) & P.8388 \\
\hline Pressure, Oil (Ruska-F/N 10029) & P.8387 \\
\hline Pressure, Oil (Ruska-F/N 5327) & P-8288 \\
\hline Ion Gage $8738 \mathrm{H}$ & 249650 \\
\hline \multicolumn{2}{|l|}{ Spinning Rotor Gages (SRG) } \\
\hline SRG 6965H (HV136) & 246538 \\
\hline SRG 11172H (HV134B) & 249583 \\
\hline SRG $8696 \mathrm{H}$ (HV134A) & 249583 \\
\hline \multicolumn{2}{|l|}{$\begin{array}{l}\text { MKS Capacitance Diaphragm } \\
\text { Gages }\end{array}$} \\
\hline $\mathrm{F} / \mathrm{Ns} 8537,8549,8547,8550$ & V174 \\
\hline $\mathrm{F} / \mathrm{Ns} 7889,7890,7893,10618$ & V183 \\
\hline \multicolumn{2}{|l|}{ Accelerometer (Vibration) } \\
\hline 6830 & $732 / 246233-90$ \\
\hline 6829$)$ & \\
\hline 11298$\}$ & $822 / 250465-92$ \\
\hline 11299 & \\
\hline \multicolumn{2}{|l|}{ Lamps Tungsten Strip } \\
\hline 7005 & $534 / 242010-88-1$ \\
\hline 7002 & $534 / 242010-88-2$ \\
\hline Thermocouple (Type S) & 248034 \\
\hline
\end{tabular}


Note: The voltage maintained by the DC Project since December 4, 1991, has been defined by the Sandia National Laboratories Josephson Voltage System, an intrinsic standard. Proper operation of this standard is checked through periodic intercomparison experiments with NIST. The system converts fre- quency to voltage by means of a superconducting solid-state array of Josephson junctions. T'he frequency used is traceable to NIST through the AC Project by means of the NIST Frequency Measurement System. 


\section{APPENDIX E \\ DOE/PSL Memoranda on Standards and Calibration Program}

\footnotetext{
DATE: DEC 191991

ATPL OF: WQD:QOB : ALF (192)

suasect: Al Standards and Calibration Program

To: Those on Attached List

There have been some Inquirles of the Department of Energy (DOE) Albuquerque Fleld Office (AL) contractors from other federal offices and contractors concerning how traceability of callbrated items is accomplished at their facilities. For continued and up-to-date response to these questions, the Primary Standards Laboratory has revised a memo (originally prepared on November 12, 1986) describing how traceability is accomplished throughout the AL complex, and this office has prepared a memo 1dentifying each contractor faclitity participating in the AL calibration system. These memos are attached and should be provided to your contractor(s) for answering future inquiries.
}

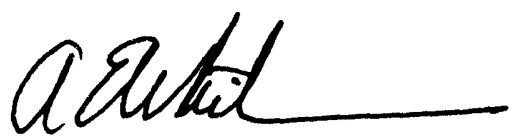

A. E. Whiteman

Director

Weapons Quality Division

At tachments 
Addressees - Memorandum dated OFC 121991

J. LaGrone, Manager, OR

D. J. Bostock, Y-12 Plant Manager \& Vice President, MES, Inc, Y-12

P. M. Hekman, Manager, SR

A. L. Schwalile, Executive Vice President, WSRC, SR

N. C. Aquilina, Manager, NV

R. Grant, EG\&G Measurement Inc. Las Vegas, NV

S. Metta, Reynolds Engtneering \& Electric Co., Mercury, NV

P. M. Rumey, Area Manager, AAO

C. C. Alley, Plant Manager, M\&H-SM Co., Inc.

J. A. Morley, Area Manager, DAO

D. E. Miche1, President, EG\&G-Mound

R. M. Nelson, Jr., Manager, RFO

J. 0. Zane, General Manager, EG\&G, RF

E. W. Bean, Area Manager, KCAO

L. W. Smith, President \& General Manager, AS-KCD

G. W. Johnson, Area Manager, PAO

R. C. Abington, General Manager, GEND

J. L. Bellows, Area Manager, LAAO

R. D. Patterson, Office Leader, Q00, MS-K307, LANL

K. A. Carlson, Area Manager, KAO

C. N. Tapp, Director, Org. 4300 , SNL

A. E. Hunt, Project Manager, WIPP

A. L. Trego, General Manager, W 


\title{
memorandum \\ Albuquerque Operations Office
}

\author{
Date: DEC $17 \mathrm{reg}$
}

AERLY TO

ATTN OF: WOD: $\varnothing O B: A I F(201)$

subject: AL Standards and Calibration Program: Traceability

To:

One of the responsibilities of the Albuguerque Field office (AL) is to insure the accuracy of test and measurement equipment used for weapons design, development, and production throughout the AI complex. To assist us in meeting this responsibility, AL has tasked the Primary Standards Laboratory (PSL) at Sandia National Laboratories, Albuguerque, to provide calibration traceability for each of the following contractors:

Allied Signal Inc., Kansas City Division

General Electric Neutron Devices Department, Pinellas Plant

Ios Alamos National Laboratory

Mason \& Hanger Silas-Mason 00 ., Inc., Pantex Plant

EGSG, Mound

EGSG, Rocky Flats Plant

Sandia National Laboratories, Albuquerque

Sandia National Laboratories, Livermore

EGSG Idaho, Inc.

DGSG Energy Measurements, Inc.

Reymolds Electrical \& Engineers $\infty$., Inc.

Martin Marietta Energy Systems, Inc., Y-12 Plant

Westinghouse Hanford

Westinghouse, Savannah River

Lawrence Livermore National Laboratory

Attached is a memo prepared by the PSL which contains excerpts fram AL Order 57XA, "Standards and Calibration Program." It describes how traceability is achieved throughout the AL complex. If you have any further questions concerning this matter, please contact this office.

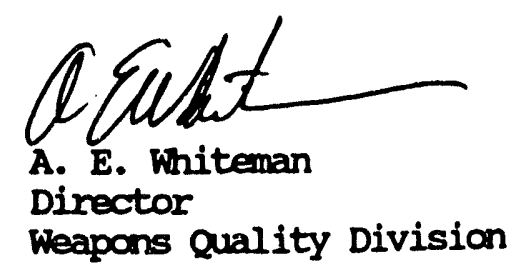

Attaciment 
To Whom It May Concern:

The Department of Energy (DOE) has the overall responsibility for all phases of the design and production of nuclear woapons, and it has placed the specific responsibility for these activities with its Albuquerque Field Office, DOE/AL.

Considering the nature of these nuclear devices, the rellablifty requirement is extremely high. All aspects of Quality Assurance are given high priority by DOE/AL in carrying out its responsibilities for the nuclear weapons program. One of the particularly important quality elements is the assurance that measuring and test equipment used throughout all phases of the program are providing proper measurements and are properly calibrated.

One of the documents relating to the requixements for the prime contractors engaged in the various phases of the nuclear weapons program is AL Order 57XA, Rev. 1, "Standards and Calibration Program" dated October 22, 1990, which addresses in substantial detail the means for assuring that proper measurement results are being obtained. This Order provides that Sandia National Laboratories (SNL) establish a Primary Standards Laboratory (PSL) and that reference level calibration laboratories be establ1shed at each of the prime contractors. These calibration laboratories are termed Contractor Standards Laboratories (CSLS). It also states the requirements for the PSL and CSL, as well as DOE/AL, their Area Offices, and other DOE Field offices, relative to the implementation of the standards and calibration program which insures the accuracy of measurements made for the nuclear weapons program.

The purpose and scope of AL Order 57XA as stated therein is as follows:

"IURPOSE. This Order assigns responsibilities and sets forth the minimum requirements for the management and operation of the Nuclear Weapons Standards and Calibration Program (NWSCP). This program provides for a system to ensure the accuracy of measurement standards and measuring and test equipment (M\&TE) used in nuclear weapons activities."

- SCOPE This order is applicable to the Department of Energy (DOE) and their contractors who are engaged in activities related to the research, design, development, preproduction, production, testing, stockpile evaluation, and retirement of nuclear weapons. Requests for deviation from any part of this Order wust be submitted to DOE Albuquerque Operations [Field]* Office (AL)."

*Inforation enclosed in brackets ([]) does not appear as such in AL57XA but is added here for clarity. 
One of the most important aspects of the AL Standards and Calibration Program is "Traceability", which is defined in paragraph 5.s. as follows:

"Traceability. The ability to relate individual measurement results through an unbroken series of calibrations to one or more of the following: 1) U. S. national standards maintained by the National Institute of Standards and Technology; 2) national standards of other countries which are correlated with U. S. national standards; 3 ) accepted values of fundamental physical constants; 4) values derived by the ratio type of self calibration techniques; 5) values obtained using nationally accepted measurement systems; or 6) comparison with consensus standards."

Paragraph 6.d. of AL Order 57XA establishes Sandia National Laboratories as the location of the Primary Standards Laboratory for the DOE/AL Weapons Complex as follows:

"SNI

"(1) Establishes the highest level metrology organization for the Nuclear Weapons Program, the PSL, by providing facilities, staff, equipment, and management for implementation of the NWSCP.

"(2) Ensures the PSL maintains an effective standards and calibration program in accordance with this order."

The requirements most closely concerned with traceability for the PSL and CSLs in this regard are covered in paragraphs 6.e. (1) and 6.e. (2), respectively as follows:

\section{"(1) Primary Standards Laboratory}

(a) coordinates the system-wide NWSCP for the DOE and their contractors by providing technical guidance, training, and consultation;

(b) publishes the PSLM; [Primary Standards Laboratory Memoranda].

(c) provides research and development program in the area of measurement technology to enable the timely provision of new measurement standards and M\&TE for a properly balanced program and measurement compatibility;

(d) develops, maintains, or specifies primary standards; 
(e) provides the certification of reference standards, when they are within their capacity and capability, to the contractors; (when neither the PSL or NIST have the capability, the PSL oversees the CSL source of outside calibration].

(f) provides technical oversight of the contractors by:

1 performing and reporting the results of technical surveys of the contractor's standards and calibration programs ;

2 periodically attending contractor surveys of arrent and potential CCLs; [Commercial Calibration Laboratories]; and

3 conducting and reporting the results of measurement audits of the contractor's metrology organization.

(g) provides immediate feedback to the appropriate DOE office when any deficiencies are identified during the technical survey; and

(h) reviews the contractor's procedures for approval and oversight of CCLs."

\section{"(2) Contractors:}

(a) provide facilities, staff, equipment, and management for implementation of the NWSCP and establish the CSL function:

(b) maintain certified reference standards; and certify and maintain working and transfer standards and M\&TE, and any associated instruments used to perform calibrations;

(c) consult with their CSL organization prior to procurement of M\&TE which may require calibration to determine whether the procurement could impact the current calibration capability;

(d) utilize the other Contractors, when necessary, to obtain calibrations that are not within their current capacity and/or capability;

(e) consult with the PSL prior to procurement of measurement standards and M\&TE which may impact the current PSL capab111ty; 
(f) maintains and provides to the PSL, documented procedures for the approval and oversight of CCLs to ensure the integrity of procured products and/or services. The extent of the approval and oversight activities for each CCL will be dependent upon the complexity of the product or service provided. CCLs will be approved to perform calibrations within specific measurement fields, ranges, and uncertainties;"

The calibrations certified by the Primary Standards Laboratory and Contractor Standards Laboratories at their respective levels are covered by the above requirements.

In accordance with AL Order 57XA, the Director of DOE/AL's Weapons Quality Division reviews and performs periodic surveys of the operation of the PSL for conformance to these requirements. In addition, the PSL performs periodic technical surveys of the CSL operations and operates a technical measurement audit program for all of the CSLs per AL Order 57XA. The PSL also routinely participates in Measurement Assurance Programs (MAPs) sponsored by the NIST to insure that the continued calibration capabilities are maintained at a high point of proficiency.

Evidence of traceability is maintained on file in the Primary Standards Laboratory along with detalled documentation of each calibration. The Primary Standards Laboratory publishes a semi-annual report of its major activities which includes a section on typical National Institute of Standards and Technology Test Numbers. Each CSL also maintains detailed evidence of traceability in their files for instruments calibrated in their laboratory.

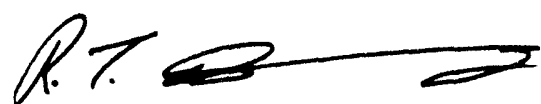

R. T. Johnson, Jr., Manager Measurement Standards Department 4340

WGTL: $4343: \mathrm{gP}$

Semi AAO 


\section{DISTRIBUTION:}

3 US Department of Energy

Albuquerque Operations Office

Attn: J. M. Eckart, Chief, QP Branch, WQ Div

J. H. Hines, Chief, PA Branch, OM Div

A. E. Whiteman, Director, WQ Div

PO Box 5400

Albuquerque, NM 87115

2 US Department of Energy

Amarillo Area Office

Attn: P. M. Ramey, Area Manager (AAO)

D. B. Buckridge, Chief, QA Branch

PO Box 30030

Amarillo, TX 79120-0030

2 US Department of Energy

Dayton Area Office

Attn: J. A. Morley, Area Manager (DAO)

I. H. Schmidt III, Chief

Weapons Quality Branch

PO Box 66

Miamisburg, $\mathrm{OH} 45343$

2 US Department of Energy

Idaho Operations Office

Attn: A. A. Pitrolo, Manager (ID)

W. N. Sato, Director, Waste Mgmt Div

785 DOE Place

Idaho Falls, ID 83402

2 US Department of Energy

Kansas City Area Office

Attn: E. W. Bean, Area Manager (KCAO)

PO Box 202

C. C. Ross, Chief, QA Branch

Kansas City, MO 64141-0202

2 US Department of Energy

Kirtland Area Office

Attn: Kathleen A. Carlson, Area Manager (KAO)

PO Box 5400

Albuquerque, NM 87115

2 US Department of Energy

Los Alamos Area Office

Attn: J. L. Bellows, Area Manager (LAAO)

528 35th Street

Los Alamos, NM 87544
2 US Department of Energy

Nevada Operations Office

Attn: N. C. Aquilina, Manager (NV)

M. P. Kunich, Director, QA Division

PO Box 98518

Las Vegas, NV 89193-8518

2 US Department of Energy

Oak Ridge Operations Office

Attn: J. W. LaGrone, Manager (OR)

G. L. Galloway, Assistant Manager

Weapons Programs

PO Box 2001

Oak Ridge, TN 37831-8764

2 US Department of Energy

Pinellas Area Office

Attn: G. W. Johnson, Area Manager (PAO)

H. F. Gregory, Chief, QA Branch

PO Box 2900

Largo, FL 34649

2 US Department of Energy

Richland Operations Office

Attn: John Wagner, Manager (RL)

R. E. Gerton, Director,

Environ, Safety, Health, and QA Div

PO Box 550

Richland, WA 99352

2 US Department of Energy

Rocky Flats Office

Attn: A. H. Pauoli, Acting Manager (RFO)

E. D. Robbins, Director, QA Div

PO Box 928

Golden, CO 80402-0928

2 US Department of Energy

San Francisco Operations Office

Attn: D. W. Pearman Jr, Manager (SAN)

J. Davis, Director, Env. Safety \& QA Div

1333 Broadway Wells Fargo Building

Oakland, CA 94612 
DISTRIBBUTION (Continued):

2 US Department of Energy Savannah River Operations Office Attn: M. P. Fiori, Manager (SR)

R. D. Rollins, Director Quality Programs Division

PO Box A

Aiken, SC 29801

4 Allied-Signal Aerospace Co.

Kansas City Division

Attn: C. W. Berry Jr, D/400-BR28

PO Box 419159

Kansas City, MO 64141-6159

3 EG\&G Idaho, Inc.

Attn: H. J. Moody, CFA 698-MS 4137

PO Box 1625

Idaho Falls, ID 83415

3 EG\&G, Energy Meas., Inc.

Attn: W. Y. Endow, MS A13-10

PO Box 1912

Las Vegas, NV 89125

3 Martin Marietta Specialty

Components, Inc.

Attn: Gayle Crist

PO Box 2908, MS-037

Largo, FL 34649

3 Westinghouse Savannah River Co.

Savannah River Laboratory

Attn: R. A. Anderson, Bldg. 736A

Aiken, SC 29802

3 Los Alamos National Laboratory

Attn: A. L. Gauler, MS D478 (2)

R. D. Patterson, K30-H

PO Box 1663

Los Alamos, NM 87544
6

Lawrence Livermore National Laboratory

Attn: R. E. Braley, L-228

Tom Miller

M. F. DeMicco, L-394

Robert Engle

J. Sedlacek

R. C. Lucena

PO Box 808

Livermore, CA 94550

1 National Aeronautics and Space Admin.

Kennedy Space Center

Attn: Kristen Riley

SI-PEI-1B

KSC, FL 32899

1 National Aeronautics and Space Admin.

White Sands Test Facility

Attn: Troy J. Estes

PO Drawer MM

Las Cruces, NM 88004

5 Mason \& Hanger-Silas Mason Co.

Attn: J. W. Noble

PO Box 30020

Amarillo, TX 79177

6 EG\&G Mound Applied Technologies, Inc. Standards and Calibrations Attn: R. L. DeHart, Bldg. 93 PO Box 3000

Miamisburg, $\mathrm{OH} 45343$

2 Reynolds Electrical \& Engr. Co.

Attn: G. A. Erickson, MS628

PO Box 98521

Las Vegas, NV 89193-9821

5 EG\&G Rocky Flats Plant

Attn: T. R. Kawamoto, Manager

Standards Lab

PO Box 464

Golden, CO 80402-0464 
DISTRIBUTION (Concluded):

4 Martin Marietta Energy Systems, Inc. Attn: J. M. Bowman, Bldg. 9211, MS-8196 PO Box 2009

Oak Ridge, TN 37831-2009

3 Westinghouse Hanford Company

Attn: Don Nelson, N1-67

PO Box 1970

Richland, WA 99352

$\begin{array}{rll}1 & 1000 & \text { B. Westwood } \\ 40 & 1040 & \text { R. T. Johnson, Jr } \\ 1 & 1041 & \text { L. J. Azevedo } \\ 1 & 1042 & \text { R. B. Pettit } \\ 1 & 1043 & \text { B. E. Barnaby } \\ 1 & 1044 & \text { J. M. Simons } \\ 1 & 1044 & \text { W. F. Windle } \\ 1 & 1044-1 & \text { L. M. Holmes } \\ 1 & 2400 & \text { J. Q. Searcy } \\ 1 & 2403 & \text { J. F. Gonzales } \\ 1 & 2484-1 & \text { C. L. Atwood } \\ 1 & 2484-1 & \text { K. J. Conrad } \\ 1 & 2500 & \text { G. N. Beeler } \\ 1 & 2600 & \text { J. H. Stichman } \\ 1 & 2700 & \text { R. A. David } \\ 1 & 2701 & \text { G. L. West } \\ 1 & 2707 & \text { V. Gabbard } \\ 1 & 2741 & \text { T. J. Baca } \\ 1 & 2741 & \text { D. O. Smallwood } \\ 1 & 2800 & \text { J. F. Jones, Actg } \\ 1 & 5100 & \text { W. C. Nickell } \\ 1 & 5200 & \text { E. E. Ives } \\ 1 & 5300 & \text { J. B. Wright } \\ 1 & 5400 & \text { H. J. Saxton } \\ 1 & 5504 & \text { D. L. McCoy } \\ 1 & 5801 & \text { K. D. Nokes } \\ 1 & 5932 & \text { R. L. Ewing }\end{array}$

$\begin{array}{ccl}1 & 5941 & \text { C. S. Lee } \\ 1 & 6300 & \text { D. E. Ellis } \\ 1 & 6302 & \text { L. E. Shephard } \\ 1 & 6303 & \text { W. D. Weart } \\ 1 & 6319 & \text { R. R. Richards } \\ 1 & 6612 & \text { A. E. Verardo } \\ 1 & 7001 & \text { E. D. Conway, Actg } \\ 1 & 7010 & \text { J. Jacobs } \\ 1 & 7715 & \text { A. L. Stanley } \\ 1 & 7732 & \text { M. M. Carroll } \\ 1 & 8200 & \text { R. J. Detry } \\ 4 & 8275 & \text { D. P. VanDyke } \\ 1 & 9200 & \text { T. A. Sellers } \\ 1 & 9300 & \text { J. E. Powell } \\ 1 & 10101 & \text { C. R. Arana } \\ 1 & 10101 & \text { L. P. Williams } \\ 1 & 12300 & \text { R. L. Schwoebel } \\ 1 & 12302 & \text { G. T. Merren } \\ 1 & 12303 & \text { J. L. Duncan } \\ 1 & 12323 & \text { R. G. Easterling } \\ 1 & 12326 & \text { M. A. Blackledge } \\ 1 & 12331 & \text { S. D. Spray } \\ 1 & 12333 & \text { R. E. Smith } \\ 1 & 12335 & \text { J. M. Sjulin } \\ 1 & 12336 & \text { E. M. Austin } \\ 1 & 12364 & \text { R. M. Oelsner, Actg } \\ 1 & 12365 & \text { E. A. Disch } \\ 1 & 12367 & \text { R. M. Oelsner } \\ 1 & 12900 & \text { C. M. Tapp } \\ 1 & 12903 & \text { J. K. Gabaldon } \\ 1 & 12908 & \text { R. R. Prairie } \\ 1 & 12911 & \text { D. W. Bushmire } \\ 1 & 8523-2 & \text { Central Technical Files } \\ 5 & 7141 & \text { Technical Library } \\ 1 & 7151 & \text { Technical Publications } \\ 10 & 7613-2 & \text { Document Processing } \\ & & \text { For DOE/OSTI } \\ & & \end{array}$



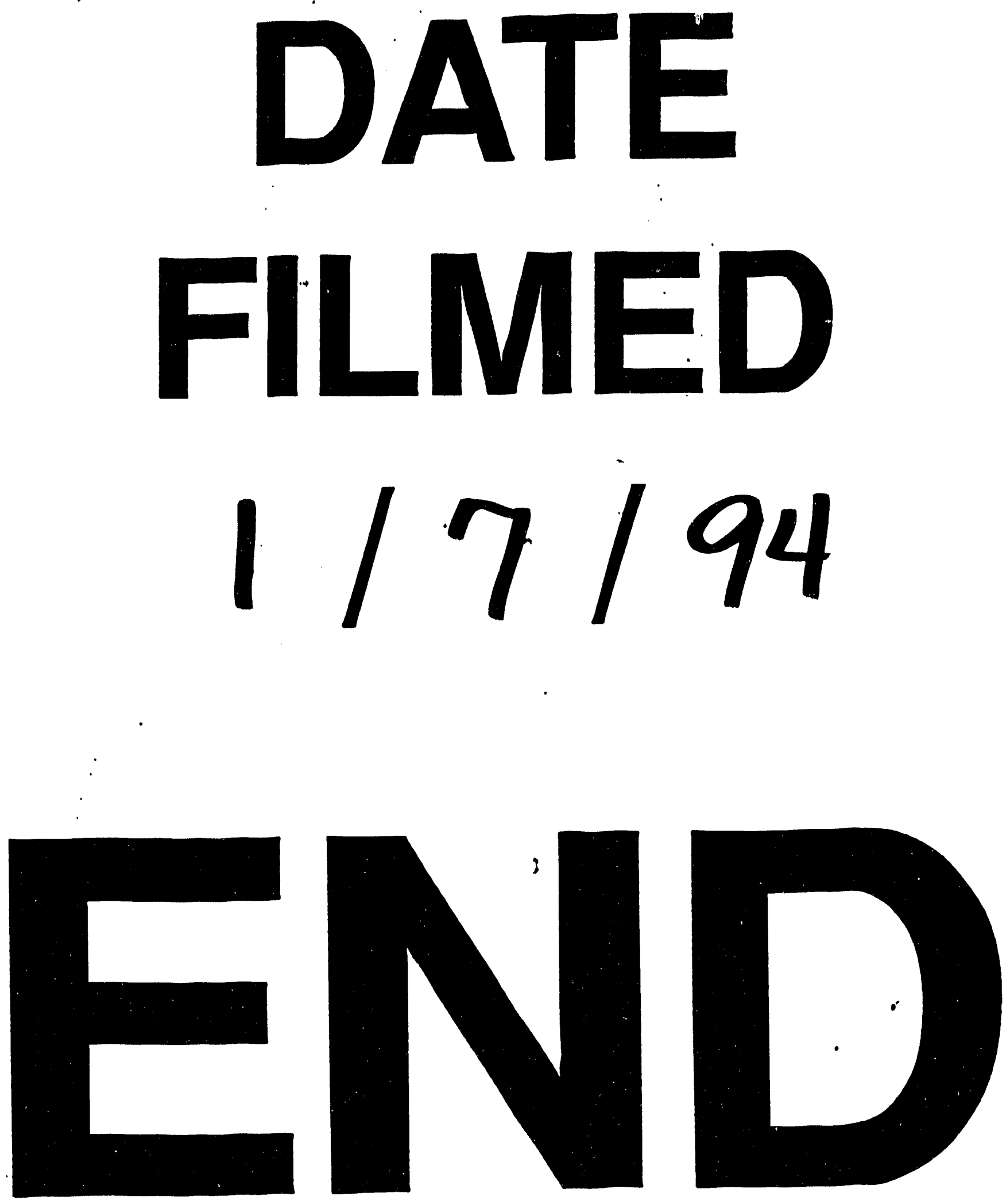
